\title{
ANALISIS PENGGUNAAN MODEL PEMBELAJARAN INQUIRY KELAS IV DI SDN PETIR 4
}

\author{
Nicken Novita Sari ${ }^{1}$, Azmy Hadisa ${ }^{2}$, Virania Ananda ${ }^{3}$ \\ Universitas Muhammadiyah Tangerang \\ azmyhadisa@gmail.com,nickennovita17@gmail.com
}

\begin{abstract}
This study aims to determine: 1) Learning models use in science subject 2) Constrains in the use of learning models 3) Student learning outcomes in the inquiry learning models 4) Student responses is the use of inquiry learning models 5) Effort to overcome obstaceles in the use of learning models to achieve specified learning objectives. This research was conducted with the 4th grade homeroom teacher with interview techniques. From the result of the interview can be obtained that 1) Learning models use in science subjects in Petir 4 Elementary School are inquiry learning models 2) The obstacles faced in using this learning model are lack of adequate teaching aids differences in the characteristic of different students who are slow in accepting and understanding the information conveyed 3) Student learning out cones inquiry learning depends on the learning media and learning method in thematic learning more children who are active in the classroom, while the teacher only prevides further information the children who complete, of course different from KTSP. In KTSP teachers are more active than students grade four 4) Student responses in use of inquiry learning model that is good response, if the teacher is active his child also actively follows the teacher, whereas if the child is left in the classroom are not condutive 5) Effort to overcome obstacles in the use of inquiry learning models, namely by providing motivation and adding props to make it more interesting when learning takes place.
\end{abstract}

Keywords: Learning Models, Inquiry, Sains

\begin{abstract}
Abstrak: Penelitian ini bertujuan untuk mengetahui: 1) Model pembelajaran yang digunakan pada mata pembelajaran ipa di SD Negeri Petir 4 2) Kendala dalam penggunaan model pembelajaran 3) Hasil belajar siswa pada pembelajaran Inquiry 4) Respon siswa dalam penggunaan model Inquiry 5) Upaya untuk mengatasi kendala dalam penggunaan model pembelajaran sehingga tercapainya tujuan pembelajaran yang telah ditentukan. Penelitian dilakukan dengan guru wali kelas IV dengan teknik wawancara. Dari hasil wawancara dapat diperoleh bahwa 1) Model pembelajaran yang digunakan pada mata pelajaran IPA di SD Negeri Petir 4 yaitu model pembelajaran Inquiry 2) Kendala yang di hadapi dalam penggunaan model pembelajaran ini yaitu kurangnya alat peraga yang memadadai dan perbedaan karakter peserta didik yang berbeda, dan peserta didik yang lambat dalam menerima dan memahami informasi yang disampaikan 3) Hasil belajar siswa pada pembelajaran inquiry itu tergantung media pembelajaran dan metode pembelajaran. Kalau tematik lebih ke anak-anak yang aktif dalam kelas, sedangkan guru hanya memberikan informasi selanjutnya anak-anak yang melengkapi. Tentunya berbeda dengan KTSP, di dalam KTSP guru lebih aktif dibanding siswa 4) Respon siswa dalam penggunaan model pembelajaran inquiry yaitu responnya baik. Kalau gurunya aktif, anaknya pun ikut aktif mengikuti gurunya. Sedangkan, jika anak di tinggal di kelas kondisi di dalam kelas tersebut menjadi tidak kondusif. 5) Upaya untuk mengatasi kendala dalam penggunaan model

Fondatia : Jurnal Pendidikan Dasar

Volume 4, Nomor 1, Maret 2020; 86-94

https://ejournal.stitpn.ac.id/index.php/fondatia
\end{abstract}


pembelajaran yaitu dengan memberikan motivasi dan menambah alat peraga agar lebih menarik saat proses pembelajaran berlangsung.

Kata Kunci: Model, Inquiry, IPA

\section{PENDAHULUAN}

Pendidikan itu sangat penting bagi setiap orang. Selama pendidikan itu diharapkan hasil atau output yang baik. Tentunya dalam proses pendidikan dipengaruhi oleh beberapa faktor pendukung demi tercapainya hasil pendidikan yang maksimal, salah satunya adalah dengan penggunaan model pembelajaran yang tepat. Pembelajaran merupakan suatu upaya yang dilakukan oleh tenaga pendidik (guru) untuk menyampaikan pengetahuan yang dimiliki dan disampaikan kepada peserta didik demi tercapainya aspek kognitif, afektif dan psikomotorik. Pembelajaran sebagai suatu sistem meliputi berbagai komponen yaitu tujuan atau kompetensi yang akan dicapai, materi/bahan ajar yang akan disampaikan, metode dan media yang digunakan serta evaluasi. Tujuan ibarat kunci yang yang merupakan hal yang ingin dicapai. Sedangkan materi atau bahan ajar adalah isi pembelajaran yang apabila dipelajari oleh peserta didik diharapkan tujuan akan tercapai. Metode adalah cara yang digunakan oleh pendidik dalam memberikan pelajaran kepada peserta didik agar lebih mudah di pahami. Evaluasi adalah suatu hal kegiatan untuk mengukur sejauh mana kualitas dan kuantitas hasil yang dicapai dari proses pembelajaran.

Model pembelajaran adalah kegiatan yang dipilih oleh tenaga pendidik dalam proses pembelajaran yang dapat memberikan kemudahan kepada peserta didik menuju tercapainya tujuan yang telah ditetapkan. Pemilihan model dan model pembelajaran yang digunakan oleh pendidik sangat dipengaruhi oleh sifat dan materi yang akan diajarkan, juga dipengaruhi oleh tujuan yang akan dicapai dalam pembelajaran. Oleh karena itu, pemilihan model pembelajaran yang digunakan dalam proses pembelajaran harus berorientasi pada tujuan pembelajaran yang akan dicapai. Tidak hanya itu, juga harus disesuaikan dengan jenis materi, karakteristik peserta didik, serta situasi atau kondisi dimana proses pembelajaran tersebut berlangsung. 
Dalam kaitannya kurikulum, pendidik, serta model pembelajaran, peserta didik menduduki posisi sentral sebab Kurikulum 2013 menuntut siswa untuk lebih aktif di dalam kelas. Dan pendidik hanya sebagai fasilitator di dalam kelas, serta model pembelajaran yang digunakan pun salah satu model pembelajaran yang berpusat pada siswa (Student centered approach). Ciri utama yang dimiliki oleh pendekatan inquiry yaitu menekankan kepada aktivitas siswa secara maksimal untuk mencari dan menemukan (menempatkan siswa sebagai subjek belajar), seluruh aktivitas yang dilakukan siswa diarahkan untuk mencari dan menemukan jawaban sendiri dari sesuatu yang dipertanyakan sehingga diharapkan dapat menumbuh sikap percaya diri (Self beliefe) serta mengembangkan kemampuan berfikir secara sistematis, logis, dan kritis atau mengembangkan kemampuan intelektual sebagai bagian dari proses mental.

Berbagai upaya dilakukan untuk meningkat mutu pendidikan antara lain dengan melengkapi sarana dan prasarana, meningkatkan kualitas guru, dan menekankan pengembangan kemampuan kepada peserta didik yang diwujudkan melalui pencapaian kompetisi siswa untuk menyesuaikan diri dan berhasil dimasa yang akan datang.

\section{METODE PENELITIAN}

Jenis penelitian yaitu deskriptif kualitatif. Penelitian ini dilaksanakan di SD Negeri Petir 4 pada mata pelajaran IPA dengan Jenis penelitian yaitu deskriptif kualitatif. Karena penelitian melihat keefektifan siswa dalam pembelajaran IPA selama didalam kelas. Penelitian yang menggunakan pendekatan kualitatif yang diungkapkan licon dan Guba dalam Mulyadi (2007 : 65) mempunyai ciri-ciri yaitu : a) latar alamiah, b) manusia sebagai alat, c) teori dan dasar, d) hasil penelitian dirunding dan disepakati bersama, e) lebih mementingkan proses dari pada hasil. Di dalam suatu penelitian ada beberapa tahap yang harus dilalui untuk mencapai hasil akhir yang diinginkan. Tahap itu mencakup : persiapan, pembuatan kuisioner, pengumpulan data, pengolahana data dan analisis data sehingga menghasilkan suatu hasil kesimpulan. 
Sesuai dengan data kualitatif disekolah tersebut, ternyata peserta didik yang diberikan sebuah persoalan setelah guru memamparkan materi ajar nya secara singkat, padat, dan jelas, mampu menyelesaikan persoalan masalahnya dengan mandiri dan kritis.

Penelitian ini terbatas pada usaha mengungkan suatu masalah atau keadaan sebagaimana adanya sehingga bersifat sekedar mengungkapkan fakta. Usaha mendeskripsikan fakta-fakta tahap permulaan tertuju pada usaha mengemukakan gejala-gejala secara lengkap didalam aspek yang diselidiki. Kemudian memeberikan penafsiran yang cukup kuat memadai terhadap fakta-fakta yang ditemukan. Berdasarkan metode penelitian yang telah ditentukan yang memusatkan pada permasalahan-permasalahan belajar yang dihadapi siswa kelas 4 SD dilanjutkan dengan usaha perbaikan kegiatan belajar mengajar.

\section{HASIL DAN PEMBAHASAN}

\section{Hasil Penelitian}

Kegiatan yang dilaksanakan pada pembelajaran IPA mengenai Rangka Manusia dengan mengunakan metode inquiri meliputi perencanaan, pelaksanaan, observasi, evaluasi, dan analisis refleksi.

Pelaksanaan pembelajaran mengenai rangka manusia dengan menggunakan metode inquiri dikelas IV SDN Petir 4 melaksanakan 2 jam pelajaran dengan alokasi waktu 2 x 35 menit. Guru dalam mengajarkan materi rangka manusia, berorientasi pada langkah-langkah pembelajaran yang menggunakan metode inquiri dalam rangka meningkatkan pemahaman siswa yang diantara lain: 1.) Orientasi siswa kepada masalah, 2.) Merumuskan masalah, 3.) Mengajukan hipotesis, 4.) Mengumpulkan data, 5.) Menguji hipotesis, dan 6.) Menarik kesimpulan. Keenam langkah-langkah pembelajaran metode inquiri tersebut terbagi dalam tiga tahapan pembelajaran yaitu tahap kegiatan awal, kegiatan inti, dan kegiatan akhir pembelajaran.

\section{PEMBAHASAN}

Inquiry berasal dari Bahasa Inggris "Inquiry", yang secara harfiah berarti penyelidikan. Carin dan Sund (1975) mengemukakan bahwa inquiry adalah the process 
of investigating a problem. Adapun Piaget mengemukakan bahwa model Inquiry merupakan model yang mempersiapkan peserta didik pada situasi untuk melakukan eksperimen sendiri secara luas agar melihat apa yang terjadi, ingin melakukan sesuatu, mengajukan pertanyaan-pertanyaan, dan mencari jawabannya sendiri, serta menghubungkan penemuan yang satu dengan penemuan yang lain, membandingkan apa yang ditemukannya dengan yang ditemukan peserta didik lain.

Sebelum melaksanakan pembelajaran, guru memberikan tes awal yang diikuti oleh siswa kelas IV SD Negeri Petir 4 yang berjumlah 30 siswa. Tes awal dimaksudkan untuk mengetahui seberapa jauh tingkat pemahaman siswa terhadap materi. Dari hasil tes awal ini diperoleh informasi bahwa secara umum siswa belum memahami materi.

Kurangnya pemahaman siswa terhadap materi disebabkan oleh pola pembelajaran sebelumnya. Pola pembelajaran yang dilakukan selama ini, guru lebih banyak mendominasi pembelajaran dengan menjelaskan materi sedangkan siswa lebih sering sebagai pendengar dari penjelasan guru. Akibat pembelajaran ini, sebagian besar siswa cenderung mnghafal sehingga pengetahuan yang diterima mudah dilupakan. Melalui belajar hafalan siswa tidak dapat mengaitkan informasi yang diperoleh kedalam struktur kognitifnya, sehingga informasi ini tidak dapat di endapkan. Selain itu siswa hanya dapat mengingat fakta-fakta yang sederhana.

Kegiatan orientasi siswa merupakan langkah untuk membina suasana atau iklim pembelajaran yang responsif sehingga siswa siap mengikuti proses pembelajaran didalam kelas. Pada setiap akhir tindakan guru memberikan ters formatif guna mengetahui sejauh mana tingkat pemahan siswa mengenai materi.

Pada kegiatan pembelajaran guru juga menggunakan alat peraga dalam memaparkan materi pelajaran agar membuat siswa lebih tertarik dan memudahkan siswa untuk memahami materi yang diajarkan. Alat peraga yang digunakan seperti replika rangka manusia. Respon siswa terhadap model pembelajaran Inquiri mendapatkan respon baik. Karena dengan menggunakan model pembelajaran Inquiri, dapat meningkatkan rasa keingintahuan siswa dalam materi yang sedang dijelaskan.

Suasana di dalam kelas, anak-anak terlihat aktif ketika kegiatan belajar berlangsung. Hal ini disebabkan karena dengan model inquiri anak lebih mandiri 
dalam menyelesaikan masalah pada materi yang diajarkan. Selain itu, dalam kurikulum 2013 menekankan orientasi pada siswa (Student Center) dalam pembelajaran. Sedangkan guru hanya sebagai fasilitator.

Kesulitan guru dalam menggunakan model pembelajaran inquiry yaitu kurangnya alat peraga yang memadai sehingga menghambat guru dalam menyampaikan materi yang akan diajarkan. Kesulitan dari siswa yang dihadapi guru adalah daya tangkap yang berbeda dari setiap peserta didik. Dimana terdapat anak yang memiliki daya tangkap yang cepat dan daya tangkap yang lambat. Rata-rata anak perempuan memiliki daya tangkap yang lebih cepat dibandingkan dengan laki-laki. Karena anak perempuan lebih fokus di dalam kegiatan pembelajaran daripada lakilaki.

Prestasi belajar siswa setelah diterapkannya model pembelajaran tersebut sedikit mengalami peningkatan, yang ditunjukan dari sikap belajar siswa yang mampu fokus dan berperan aktif dalam pembelajaran berlangsung.

Selanjutnya, perencanaan pembelajaran di SD Negeri Petir 4 diharapkan tersedianya alat peraga yang memadai untuk menunjang kegiatan belajar siswa agar tercapai tujuan pembelajaran yang diharapkan dengan baik.

Pernyataan:

\begin{tabular}{|c|l|c|c|l|}
\hline No & \multicolumn{1}{|c|}{ Pernyataan } & Ya & Tidak & \multicolumn{1}{|c|}{ Keterangan } \\
\hline 1 & $\begin{array}{l}\text { Apakah anak-anak merasa puas } \\
\text { dengan adanya model } \\
\text { Pembelajaran yang bapak } \\
\text { gunakan? }\end{array}$ & $\checkmark$ & & $\begin{array}{l}\text { Puas. Karena saya mengajar pun dengan } \\
\text { penuh semangat, sehingga anak-anak } \\
\text { pun juga tidak merasa bosan dengan } \\
\text { model pembelajaran yang saya gunakan. }\end{array}$ \\
\hline 2 & $\begin{array}{l}\text { Apakah model pembelajaran } \\
\text { yang bapak gunakan dapat } \\
\text { menghilangkan rasa bosan saat } \\
\text { proses Kegiatan Belajar } \\
\text { Mengajar }\end{array}$ & $\checkmark$ & & $\begin{array}{l}\text { Ya. Karena pada saat kegiatan belajar } \\
\text { terkadang kita menonton menggunakan } \\
\text { infokus. Misalnya dalam mata pelajaran } \\
\text { IPS tentang Planet-planet. Maka anak- } \\
\text { anak lebih tertarik untuk menonton } \\
\text { daripada kita menjelaskan. }\end{array}$ \\
\hline 3 & $\begin{array}{l}\text { Apakah model pembelajaran } \\
\text { yang bapak gunakan akan } \\
\text { memotivasi anak untuk belajar } \\
\text { semakin meningkat? }\end{array}$ & $\checkmark$ & $\begin{array}{l}\text { Tentu. Karena anak sangat antusias } \\
\text { pada saat menggunakan model } \\
\text { pembelajaran tersebut dalam pelajaran } \\
\text { IPA }\end{array}$ \\
\hline
\end{tabular}




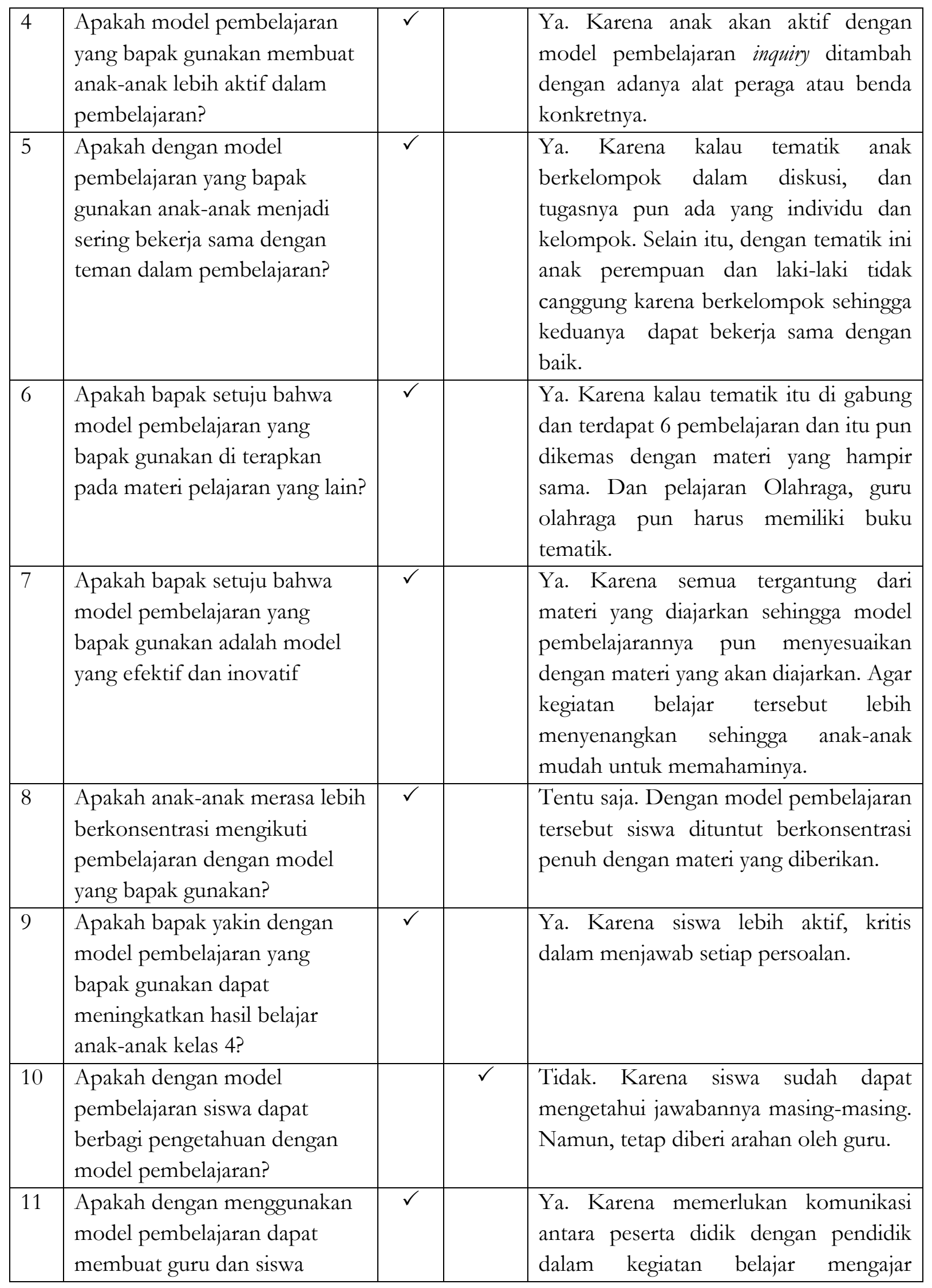




\begin{tabular}{|c|c|c|c|}
\hline & interaktif? & & berlangsung. \\
\hline 12 & $\begin{array}{l}\text { Apakah anak-anak dapat } \\
\text { menjawab pertanyaan guru } \\
\text { setelah belajar dengan } \\
\text { Menggunakan model } \\
\text { pembelajaran yang bapak } \\
\text { terapkan? }\end{array}$ & $\checkmark$ & $\begin{array}{l}\text { Ya. Karena siswa sendiri yang mencari } \\
\text { jawaban-jawabam dari persoalan yang } \\
\text { ada. }\end{array}$ \\
\hline 13 & $\begin{array}{l}\text { Apakah anak-anak merasa } \\
\text { banyak materi yang belum } \\
\text { paham ketika menggunakan } \\
\text { model pembelajaran? }\end{array}$ & $\checkmark$ & $\begin{array}{l}\text { Terkadang ya. Karena sebagian siswa } \\
\text { daya paham setiap siswa dalam mencari } \\
\text { jawabannya sendiri terhadap materi } \\
\text { yang diajarkan. }\end{array}$ \\
\hline
\end{tabular}

\section{KESIMPULAN}

Berdasarkan hasil penemuan dan pembahasan, maka hasil penelitian ini dapat disimpulkan bahwa dengan menggunakan metode inquiri dapat meningkatkan pemahaman konsep pada siswa kelas IV SD Negeri Petir 4 hal ini dapat dilihat dengan keaktifan para siswa dalam menjawab setiap persoalan masalah yang diberikan pendidik kepadanya. Model di desain secara baik akan memberikan makna yang hamper sama dengan benda aslinya hal ini dikarenakan dengan melihat benda aslinya yang berarti dapat dipegang, maka peserta didik dapat lebih mudah dalam mempelajarinya. Misalnya dalam pembelajaran IPA siswa dapat melihat secara langsung bagian-bagian tubuh manusia melalui sebuah model. Biasanya model semacam ini dapat dibuat dengan skala $1: 1$ artinya benda yang dilihat memiliki besar yang persis sama benda aslinya atau dapat juga dengan skala yang lebih kecil, tergantung pada benda apa yang akan dibuat modelnya. Bahan ajar semacam ini tidak dapat berdiri sendiri melainkan harus dibantu dengan bahan tertulis agar memudahkan guru dalam mengajar maupun siswa dalam belajar. Dalam memanfaatkan model sebagai bahan ajar harus menggunakan kompetensi dasar dalam kurikulum sebagai acuan nya. 


\section{DAFTAR PUSTAKA}

Agus Budi, dan Nurul Ahmad, "Penerapan Model Inquiry dalam Meningkatkan Hasil Belajar Siswa Pada Mata Pelajaran IPA di Kelas IV SDN 3 Siwalempu”, Sulawesi: Jurnal Kreatif Tadulako, Vol. 4, No. 2 (2016), [http://www.neliti.com] Djamrah dan Zain. (2006). Belajar dan Pembelajaran. Jakarta: Rieneka Cipta.

Djamrah dan Zain. (2006). Belajar Dan Pembelajaran. Jakarta: Rineka Cipta. Hasibuan. (1994). Strategi Belajar Mengajar. Jakarta: Remaja Karya.

Hendri, Wawancara, Tangerang 27 November 2019.

Majid, Abdul. (2009). Perencanaan Pembelajaran. Bandung: Remaja Rosda Karya.

Mulyasa. (2008). Menjadi Guru Profesional, Jakarta: Prenada Media Group.

Slameto. (2010). Belajar dan Faktor-faktor yang mempengarubi. Yogyakarta: Rineka Cipta. 